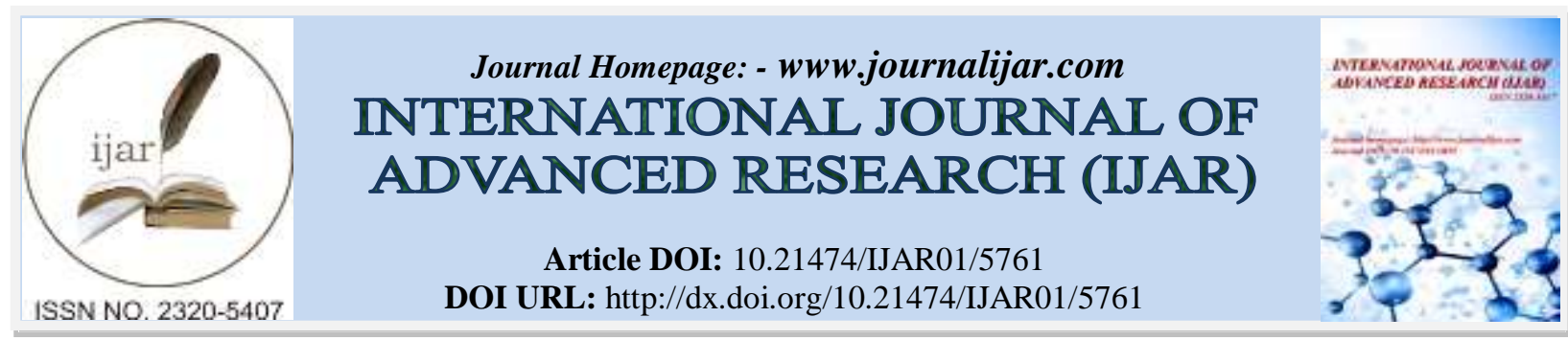

RESEARCH ARTICLE

\title{
STUDY OF EFFECT OF ADENOTONSILLECTOMY IN CHILDREN WITH SLEEP DISORDERD BREATHING USING PEDIATRIC SLEEP QUESTIONNAIRE.
}

\author{
Dr. Arshed Ali ${ }^{1}$, Dr. Jasif Nisar ${ }^{1}$, Dr. Ihsan Ali ${ }^{2}$, Dr. Salma Gull ${ }^{3}$ and Prof. Dr Rauf Ahmad ${ }^{4}$. \\ 1- Post-Graduate Resident, Department Of ENT AND HNS, GMC Srinagar. \\ 2- Assistant professor, department of ENT AND HNS, GMC Srinagar. \\ 3- Post-graduate resident, department of PATHOLOGY, SKIMS, SOURA, Srinagar. \\ 4- Head Of Department, ENT AND HNS, GMC Srinagar.
}

\section{Manuscript Info}

\section{Manuscript History}

Received: 03 September 2017

Final Accepted: 05 October 2017

Published: November 2017

Keywords:-

Sleep disorderd

breathing,PSQ(pediatric sleep

questionnaire),Adenotonsillectomy

\section{Abstract}

Background: This prospective study was conducted to clinically evaluate Sleep Disorderd Breathing children after Adenotonsillectomy Using Pediatric Sleep Questionnaire.SDB can lead to substantial morbidities, affecting the central nervous system (CNS), the cardiovascular and metabolic systems, and somatic growth, ultimately leading to reduced quality of life.

Methods: This prospective study was conducted in 47 patients in the Department of Otorhinolaryngology Head and Neck Surgery, Government Medical College and associated SMHS Hospital Srinagar. In this study, we included the patients with SDB in pediatric age group, who visited in our OPD.Pediatric Sleep questionnaire was used pre-operatively, at 2 and 6 months after surgery.

Results: Our study group comprised of total 47 patients with majority of patients with in age group of 5-7 years, males were $29(61.70 \%)$ and females were $18(38.30 \%)$. Snoring, mouth breathing and frequent awakening were the most common presenting symptoms, $89.36 \%$, $85.11 \%$ and $70.21 \%$ respectively. Juglodigastric Lymphadenopathy,High Arched Palate were the most common signs, $85.11 \%$ and $78.12 \%$ respectively. Paediatric sleep questionnaire (PSQ) was used pre-operatively, at 2 months, at 6 months.Preoperative score showed that majority of patients $41(87.23 \%)$ had score between 8-15 i.e, moderate SDB and 6 (12.77\%) patients had score between 16-22 i.e,severe SDB .Mean PSQ value preoperativly,at 2 months and at 6 months were $12.27,3.38,2.13$ respectivelly, showing improvement in the degree SDB after surgical intervention.

Conclusion: Based on the observations made in the study we concluded that there was a significant improvement in Pediatric sleep questionnaire (PSQ scale was used for diagnostic purpose preoperatively, at 2 months and at 6 months, showed the mean score of $12.28,3.68$ and 2.36 respectively), which shows there is significant improvement in post operative scores as compared to preoperative score and hence post operative symptoms after surgical intervention. 


\section{Introduction:-}

Sleep-disordered breathing (SDB) is a common entity in children and includes a continuum of sleep-related breathing disturbances, SDB encompasses the spectrum of sleep disorders ranging in severity from primary snoring to obstructive sleep apnea(OSA), OSA on the severe end of the spectrum, and is generally diagnosed clinically based on signs and symptoms. ${ }^{1}$ The term sleep disordered breathing (SDB) refers to group of respiratory disorders that occur or are exacerbated during sleep. Sleep Disordered Breathing (SDB) is characterized by: abnormal respiratory patterns (e.g. the presence of apneas or hypopneas) or insufficient ventilation during sleep. Sleep disorder breathing is an umbrella term for several chronic conditions in which partial or complete cessation of breathing occur many times throughout the night, resulting in daytime sleepiness or fatigue that interferes person's ability to function and reduces quality of life. ${ }^{2}$

Classification of $\mathrm{SDB}^{3}$

1. Primary snoring

2. Upper airway resistance syndrome (URAS)

3. Obstrutive sleep apnoea syndrome (OSAS)

OSA is the most common type of SDB. The prevalence of OSAS in children is estimated to be $2 \%$. Children with sleep disordered breathing (SDB) can manifest a continuum from simple snoring and upper airway resistance syndrome to obstructive sleep apnea (OSA) $)^{4,5}$. SDB has also been associated with decreased cognitive skills, decreased quality of life (QOL), behavior disturbances and neurocognitive changes in children. ${ }^{6}$ Medical conditions and anatomical abnormalities can predispose to SDB and OSA, including adenotonsillar hypertrophy, obesity, trisomy 21, cerebral palsy, and craniofacial anomalies. ${ }^{7-12}$. The aim of our study was to evaluate the paediatric patients clinically, and to assess the impact of surgical intervention on SDB symptoms using pediatric sleep questionnaire.

\section{OBJECTIVE:-}

To study the effect of adenotonsillectomy in children with sleep disorderd breathing using pediatric sleep questionnaire.

\section{Material and Method Of Study:-}

This prospective study was conducted in the Department of Otorhinolaryngology Head and Neck Surgery, Government Medical College and associated SMHS Hospital Srinagar from july 2015 to july 2017. In this study we included the patients with SDB in pediatric age group, who visited in our OPD.

Diagnostic methods that have been scientifically evaluated include history and physical examination, pulse oximetry, abbreviated polysomnography, and full polysomnography

1. History and physical evaluation ${ }^{13-15}$

2. Sleep history screening for snoring should be a part of routine health care visit. A more detailed history regarding labored breathing during sleep, observed apnea restless sleep, diaphoresis, anuresis, excessive daytime sleepiness and behaviour and learning problem (Including Attention deficit and hyperactivity disorder) should be obtained. On physical examination finding during wakefulness are often normal. There may be nonspecific finding related to Adenotonsillar hypertrophy such as mouth breathing nasal obstruction during wakefulness, adenoid facies and hyponasal speech. Evidence of complication of OSAS may be present such as systemic hypertension and poor growth.

3. Polysomnography in patients who cooperates ${ }^{16}$

All the patients with adenotonsillar hyperplasia who fail to respond to conservative management were subjected to adeno-tonsillectomy surgery.

Evaluation of children with symptoms of OSAS is also based on the sleep pediatric sleep questionnaires (PSQ) developed by University of Michigan accepted on $4^{\text {th }}$ October 1999. They validate the questionnaire scale for OSAS and relate symptoms including three prominent symptom complexes: Snoring, Excessive daytime sleepiness and inattentive or hyperactive behavior. Both sensitivity and specificity were high when 8 or more positive answers to the 22 questions were considered abnormal. Pediatric Sleep Questionnaires (PSQ Scale Was Used For Diagnostic Purpose Pre-Operatively,At 2 Months And At 6 Months. 


\section{Results:-}

This prospective hospital based study was conducted in the Department of Otorhinolaryngology, Head and Neck Surgery, Government Medical College and Associated SMHS Hospital Srinagar. A total of 47 patients were included with following details.

Table 1:- Age wise Distribution of patients

\begin{tabular}{|l|l|l|}
\hline Age Group(Years) & No. Of Patients & \%age \\
\hline $2-4$ & 12 & $25.53 \%$ \\
\hline $5-7$ & 23 & $48.94 \%$ \\
\hline $8-10$ & 8 & $17.02 \%$ \\
\hline $11-13$ & 3 & $6.38 \%$ \\
\hline $14-16$ & 1 & $2.23 \%$ \\
\hline
\end{tabular}

Table 1 showing that our study group comprised of total 47 patients with majority of patients with in age group of 5-

7 years. With youngest patient was 3 years and eldest was 15 years old.

Table 2:- Sex Wise distribution of Patients

\begin{tabular}{|l|l|l|}
\hline SEX & No. Of Patients & \%age \\
\hline Male & 29 & $61.70 \%$ \\
\hline Female & 18 & $38.30 \%$ \\
\hline Total & 47 & $100 \%$ \\
\hline
\end{tabular}

Table 2 showing that majority of patients in our study males were $29(61.70 \%)$ and females were $18(38.30 \%)$.

Table 3:- Distribution of presenting Symptoms

\begin{tabular}{|l|c|c|}
\hline \multicolumn{1}{|c|}{ Symptoms } & No. Of Patients & \%age \\
\hline Snoring & 42 & $89.36 \%$ \\
\hline Mouth Breathing & 40 & $85.11 \%$ \\
\hline Frequent Awakening & 33 & $70.21 \%$ \\
\hline Poor school Performance & 19 & $40.43 \%$ \\
\hline Irritable Behavior & 26 & $55.32 \%$ \\
\hline Nocturnal Enuresis & 19 & $40.43 \%$ \\
\hline Chocking Episodes & 24 & $51.06 \%$ \\
\hline Day time Sleepiness & 13 & $27.66 \%$ \\
\hline Difficulty In getting up in the morning & 26 & $55.32 \%$ \\
\hline Growth Retardation & 5 & $10.64 \%$ \\
\hline Recurrent Upper airway Infections & 31 & $65.96 \%$ \\
\hline Runny Nose & 32 & $68.09 \%$ \\
\hline Difficulty in Feeding & 18 & $38.30 \%$ \\
\hline Hyperactive Behavior & 22 & $46.81 \%$ \\
\hline Otalgia & 26 & $55.31 \%$ \\
\hline Ear fullness & 11 & $23.40 \%$ \\
\hline
\end{tabular}

Table 3: showing that in our study group comprised of 47 patients Snoring, mouth breathing and frequent awakening were the most common presenting symptoms with $89.36 \%$ presented with Snoring, $85.11 \%$ presented with mouth breathing and $70.21 \%$ presented with frequent awakening. Other symptoms shown in the table with \%age.

Table 4:- Distribution of Clinical Finding on Examination

\begin{tabular}{|l|c|c|}
\hline \multicolumn{1}{|c|}{ Signs of Patients } & No. of Patients & \%age \\
\hline Pinched Nose & 18 & $38.30 \%$ \\
\hline High Arched Palate & 37 & $78.72 \%$ \\
\hline Over Crowded Teeth & 17 & $36.17 \%$ \\
\hline Retracted Tympanic membrane & 16 & $34.04 \%$ \\
\hline Glue ear & 2 & $4.26 \%$ \\
\hline Hypertrophic Inferior Turbinate & 23 & $48.94 \%$ \\
\hline Deviated Nasal Septum & 7 & $14.89 \%$ \\
\hline Jugulodigastric Lymph Adenopathy & 40 & $85.11 \%$ \\
\hline
\end{tabular}




\begin{tabular}{|l|c|c|}
\hline Pale Mucosa & 22 & $46.80 \%$ \\
\hline Blue colour Turbinate & 21 & $44.68 \%$ \\
\hline
\end{tabular}

Table 4 showing that in our study group comprised of 47 patients Juglodigastric Lymph Adenopathy, High Arched Palate was the most common finding on examination with $85.11 \%$ Juglodigastric Lymph Adenopathy and $78.12 \%$ High Arched Palate. The others finding on examination presented in the table with \%age.

Table 5:- Pediatric Sleep Questionnaire (PSQ) Scale Score is used to investigate the presence of childhood SDB and prominent symptom complexes.

Preoperative Score
\begin{tabular}{|l|l|l|}
\hline PSQ Scale Score & No. Of Patients N=47 & \%age \\
\hline$<8$ & nil & Nil \\
\hline $8-15$ & 41 & $87.23 \%$ \\
\hline $16--22$ & 6 & $12.77 \%$ \\
\hline
\end{tabular}

PSQ = Pediatric Sleep Questionnaire Score

Table 5 showing that in our study group, the PSQ scale used pre-operatively showed the majority of the patients $41(87.23 \%)$ having score in $8-15$ range indicating that SDB is present.

Table 6:- Pediatric Sleep Questionnaire Scale (PSQ) used in postoperative period at 2 months and at 6 months

\begin{tabular}{|l|l|l|l|l|}
\hline Post op PSQ scale & 2 months $(\mathbf{n}=\mathbf{4 7})$ & Percentage & $\mathbf{6}$ months(n=47) & Percentage \\
\hline$<8$ & 47 & $100 \%$ & 47 & $100 \%$ \\
\hline $8-15$ & 0 & $0 \%$ & 0 & $0 \%$ \\
\hline $16-22$ & 0 & $0 \%$ & 0 & $0 \%$ \\
\hline
\end{tabular}

Table 6 showing that postoperative PSQ score improved significantly suggesting improvement in symptoms of SDB postoperatively.

Table 7:- Comparison of Pediatric Sleep Questionnaire Score (PSQ) Score preoperative, at 2 months and at 6 months

\begin{tabular}{|l|l|l|l|l|l|}
\hline \multicolumn{2}{|l|}{ Descriptive Statistics } & \multicolumn{2}{l|}{ 95\% confidence interval } \\
\hline & mean & Std. Deviation & N & Lower Bound & Upper Bound \\
\hline PSQ preoperative & 12.28 & 2.092 & 47 & 11.662 & 12.891 \\
\hline PSQ 2 months & 3.68 & 1.520 & 47 & 3.235 & 4.127 \\
\hline PSQ 6 months & 2.36 & 1.241 & 47 & 1.997 & 2.726 \\
\hline P value for PSQ pre op vs PSQ at 2 months <0.001 (repeated measures ANOVA,Bonferroni post-hoc) \\
\hline P value for PSQ at 2 months vs PSQ at 6 months <0.001 (repeated measures ANOVA,Bonferroni post-hoc) \\
\hline
\end{tabular}

Table 7 showing that in our study group of 47 patient the Pediatric Sleep Questionnaire preoperative score was (mean 12.28) high but postoperative score reduced to mean 3.68 at 2 months and mean 2.36 at 6 months. This signify that there is significant improvements in SDB symptoms after surgery (adenotonsillectomy)

\section{Discussion:-}

Sleep-disordered breathing (SDB) represents a spectrum of sleep-related diseases resulting in nocturnal breathing difficulty, ranging from intermittent and habitual snoring (HS) to obstructive sleep apnea syndrome (OSAS). SDB is extremely common; estimates suggest that HS and OSAS occur in $10 \%$ and $2 \%$ to $4 \%$ of children, respectively. ${ }^{17}$ Untreated pediatric SDB is associated with numerous comorbidities that include lowered IQ, decreased executive function, behavioural problems, secondary nocturnal enuresis, and cardiopulmonary dysfunction. ${ }^{18}$

In the present study, we had 47 patients with majority of patients were males $29(61.70 \%)$ and females were 18(38.30\%), with majority of patients were in the age group of 5-7 yrs (48.94\%)Table 1-2 .JOSE MARIO DE LIMA JUNIOR et $\mathbf{a l}^{\mathbf{1 9}}$ also found in their study that $56.2 \%$ were males and $43.8 \%$ were females with mean age of 6 yrs and 6 months.RON B.et $\mathbf{a l}^{\mathbf{2 0}}$ also found in their study that $51 \%$ were males and $49 \%$ were females with mean age of $6.3 \mathrm{yrs}$ i.e, the male preponderance.VALERIE A et $\mathbf{a l}^{\mathbf{2 1}}$ found in their study that $53 \%$ were females and $47 \%$ were males with mean age of 6 yrs.It is a consensus among various authors that adenoid or adenotonsillary hyperplasia is the main cause of SDB among children ${ }^{22-25}$ adenoidectomy (or adenotonsillectomy) have been, therefore, procedures of choice for the treatment of most cases of SDB in the pediatric population. 
In the present study of 47 patients Snoring, mouth breathing and frequent awakening were the most common presenting symptoms with $89.36 \%$ presented with Snoring, $85.11 \%$ presented with mouth breathing and $70.21 \%$ presented with frequent awakening. Juglodigastric Lymphadenopathy,High Arched Palate were the most common signs with $85.11 \%$ Juglodigastric Lymphadenopathy and $78.12 \%$ High Arched Palate(table 3,4).NIRAN.A et al ${ }^{26}$ in their study of 100 children found that majority of patients had symptoms of snoring, mouth breathing ,choking,gasping and majority had signs of adenoid facies, high arched plate and increased tonsillar size. VALERIE A et $\mathbf{a l}^{\mathbf{2 1}}$ in their study of 60 patients found that 51 (85\%) patients presented with snoring ,51(85\%) patients presented with mouth breathing, grade 3 and grade 4 tonsil size was seen in $50 \%$ and $36 \%$ patients respectively. In the present study we also used paediatric sleep questionnaire (PSQ) pre-operatively, at 2 months, at 6 months.Pre-operative score showed that majority of patients $41(87.23 \%)$ had score between 8-15 i.e, moderate SDB and $6(\mathbf{1 2 . 7 7 \%})$ patients had score between 16-22 i.e,severe SDB.Mean PSQ value pre-operativly,at 2 months and at 6 months were $12.27,3.38,2.13$ respectivelly, showing improvement in the degree SDB(table $5,6,7)$

\section{Conclusion:-}

Based on the observations made in the study,we concluded that there was a significant improvement in Pediatric sleep questionnaires (PSQ scale was used for diagnostic purpose pre-operatively, at two months and at six months, showed the mean score of $12.28,3.68$ and 2.36 respectively), which shows there is significant improvement in post operative score as compared to preoperative score and hence post operative symptoms after surgical intervention.

\section{Bibliography:-}

1. Guilleminault C, Pelayo R, Leger D, Clerk A, Bocian RC. Recognition of sleep-disordered breathing in children. Pediatrics 1996;98:871-882.

2. American Thoracic Society. Standards and indications for cardiopulmonary sleep studies in children. Am $\mathbf{J}$ Respir Crit Care Med 1996; 153: 866-878.

3. Coleman JA. Pathophysiology of snoring and obstructive sleep apnea: airway dynamics. In: Fairbanks DNK, Mickelson SA, Woodson BT, eds. Snoring and Obstructive Sleep Apnea. 3rd ed. Philadelphia: Williams \& Wilkins Co., 2003:19.

4. Ali NJ, Pitson DJ, Snoring. Sleep disturbance, and behavior in 4-5 year olds. Arch Dis Child 1993; 68: $360-366$.

5. Redline S, Tishler PV, Schluchter M, Aylor J, Clark K, Graham G. Risk factors for sleep disordered breathing in children: associations with obesity, race, and respiratory problems. Am J Respir Crit Care Med 1999; 159: 1527-1532.

6. Mitchell RB, Kelly J. Behavior, neurocognition and quality-of-life in childrenwith sleep-disordered breathing. Int J Pediatr Otorhinolaryngol 2006;70:395-406.

7. Mitchell RB, Call E, Kelly J. Diagnosis and therapy for airway obstruction in children with Down syndrome. Arch Otolaryngol Head Neck Surg 2003;129:642-645.

8. Mitchell RB, Kelly J. Adenotonsillectomy for obstructive sleep apnea in obese children. Otolaryngol Head Neck Surg 2004;131:104-108.

9. Kotagal S, Gibbons VP, Stith JA. Sleep abnormalities in patients with severe cerebral palsy. Dev Med Child Neurol 1994;36:304-311.

10. Lam DJ, Jensen CC, Mueller BA, Starr JR, Cunningham ML, Weave EM.Pediatric sleep apnea and craniofacial anomalies: a population-basedcase-control study. Laryngoscope 2010;120:2098-2105.

11. Costa DJ, Mitchell R. Adenotonsillectomy for obstructive sleep apnea in obese children: a meta-analysis. Otolaryngol Head Neck Surg 2009;140:455-460.

12. Myatt HM, Beckenham EJ. The use of diagnostic sleep nasendoscopy in the management of children with complex upper airway obstruction.Clin Otolaryngol Allied Sci 2000;25:200-208.

13. Guilleminault C, Korobkin R, Winkle R. A review of 50 children with obstructive sleep apnea syndrome. Lung 1981; 159: 275-287.

14. Brouilette R, Hanson D, David R, Klemka L, Szatkowski A, Fernbach S, Hunt C. A diagnostic approach to suspected obstructive sleep apnea in children. J Pediatr 1984; 105: 10-14.

15. Stradling JR, Thomas G, Warley AR, Williams P, Freeland A. Effect of adenotonsillectomy on nocturnal hypoxaemia, sleep disturbance, and symptoms in snoring children. Lancet 1990; 335: 249-253.

16. Rosen CL. Clinical features of obstructive sleep apnea hypoventilation syndrome in otherwise healthy children. Pediatr Pulmonol 1999; 27: 403-409. 
17. Goldbart AD, Tal A. Inflammation and sleep disordered breathing in children:a state-of-the-art review. Pediatr Pulmonol 2008;43:1151-1160.

18. Cardiorespiratory sleep studies in children. Establishment of normative data and polysomnographic predictors of morbidity. American Thoracic Society. Am J Respir Crit Care Med 1999;160:1381.

19. Jose Mario de Lima Junior, Vivane Carvalho da Silva, Marcos Rabelo de Freitas Long term results in the life quality of children with obstructive sleep disorders Rev Bras Otorrinolaringol 2008; 74(5): 718-24.

20. Ron B. Mitchell James Kelly. Outcomes and Quality of life following Adenotonsillectomy for sleep-dis0rdered breathing in children ORL 2007; 69: 345-348.

21. Valerie A. Flanary, MD, Long-Term Effect of Adenotonsillectomy on Quality of Life in Pediatric Patients, Laryngoscope 113:1639-1644,2003.

22. Leach J, Olson J, Hermann J, Manning S. Polysomnographic and clinical findings in children with obstructive sleep apnea. Arch Otolaryngol Head Neck Surg 1992;118(7):741-4.

23. Reilly JS. Apnéia obstrutiva do sono e ronco em crianças: noções gerais. Em: Sih T, Chinski A, Eavey R, editores. III Manual de Otorrinolaringologia Pediátrica da IAPO. 2003;p. 59-66.

24. Messner AH, Pelayo R. Pediatric sleep-related breathing disorders. Am J Otolaryngol 2000;21(2):98-107.

25. Weckx LLM, Weckx LY. Respirador bucal: causas e conseqüências. Rev Bras Med 1995;52(8):863-74.

26. Nira A. Goldstein, MD, MPH; Dimitre G. Stefanov, PhD; Katharina D. Graw-Panzer, MD;Samir A. Fahmy, MD; Sherry Fishkin, MD; Alison Jackson, BA;Jennifer S. Sarhis, BS; Jeremy Weedon, PhD , Validation of a Clinical Assessment Score for Pediatric Sleep-Disordered Breathing. . Laryngoscope, 122:2096-2104, 2012. 